\title{
Humble Opinions on Inclusive Educational Idea
}

\author{
Jiang Zhu \\ School of Foreign Languages, Changchun University of Science and Technology \\ Changchun 130022, China \\ Tel: 86-431-8558-3033 E-mail: zhujiang98@163.com \\ Lijuan Wang \\ School of Science, Changchun University of Science and Technology \\ Changchun 130022, China \\ E-mail:wlj15@163.com
}

\begin{abstract}
Inclusive education refers to including all the people to realize the democracy, justice and diversity of education. Inclusive educational idea means to make all the students have equal opportunities in enjoying high-quality education and make every student have all-round development, reflecting the yearning for the education without exclusion and discrimination of people from different countries, nationalities and beliefs. Inclusive educational idea should be spread widely and put into effect.
\end{abstract}

Keywords: Inclusive educational idea, Challenge, Countermeasure

\section{Introduction}

Inclusive education means to include all the people to realize the democracy, justice and diversity of education. As a new educational idea, it aims at realizing the justice of education, and embodies the idea of "education without distinction". Yuan Yimin, who worked in UNESCO, pointed out, "Inclusive education does not refer to a certain kind of students, children of immigrants, poor people or other disadvantaged groups. It refers to all the people. Everyone has the chance to acquire high-quality education. The different needs of different people should be fully considered." Inclusive educational idea means to make all the students have equal opportunities in enjoying high-quality education and make every student have all-round development on the basis of admitting the differences in individual characters. Carrying out this idea is the inevitable trend of the development of international society, and it is also the only way for China to build a nation of powerful education. Carrying out this idea challenges the traditional educational idea in China. We should consider all these things.

\section{Putting forward inclusive educational idea}

The original intention of putting forward inclusive educational idea began from changing the traditional segregating education. In the 1960s, traditional special education was to arrange disabled students to study in schools set for them specially to show the society's care for them. Because the disabled students stayed together and were separated from the society, such kind of special education became an obstacle for the disabled students to return to the society. Because of the introspection on binary system and the inspiration of human rights, some northern European countries tried to accept all students, including disabled students, to study in common school. This measurement bred a new educational idea, inclusive educational idea.

In 1975, the U.S. issued Education for All Handicapped Children Act, putting forward the idea of "returning to the mainstream" for disabled students. According to the Act, disabled students are placed in common school to be educated. They will study and live together with physically-sound students. Later, UK and Australia issued similar laws and regulations, supporting disabled students to be educated with physically-sound students. This revolution in special education laid the foundation for putting forward inclusive educational idea.

In 1990, The World Conference on Education for All passed The Declaration of World Education for All: Meeting Basic Needs of Learning. The Declaration pointed out that special attention should be paid to the learning needs of disabled people. Steps should be taken to provide equal opportunities of education for different kinds of people, and this kind of education should become a constituent part of the educational system. This thought is the embryonic form of inclusive educational idea.

In 1994, The World Conference on Special Needs Education was held in Salamanca, Spain. The conference passed Salamanca Declaration --- The Principle, Method and Practice of Education of Special Needs. The conference put forward inclusive educational idea for the first time, and it clearly expressed 5 principles: Every student has the basic right of receiving education; Every student has his/her individual character, interest, ability and learning need; The students' differences in characters and other aspects should be considered in education; 
Students with special requirements should have the opportunities to study in ordinary school; Inclusive school is the most effective way of fighting against discrimination, establishing inclusive community where everybody is welcome and realizing overall education. From then on, after less than 20 years, the scope of inclusive education has surpassed the students who are physically disabled. It also includes the students who have obstacles in their mind, or who have defects in their morality, or who have difficulties in their learning. As a new educational idea, inclusive educational idea is accepted by each nation.

In 2005, UNESCO issued Guide to Inclusive Education: Access to Ensuring Education for All People, defining inclusive education: Inclusive education is to reduce the exclusion inside and outside educational system by increasing learning, culture and community participation. Facing the diverse needs of all learners, inclusive education is the process of reacting to the needs. According to this definition, inclusive education tries to make all the people receive the same good quality education, especially to help those students who might be marginalized or discriminated because of their physical, mental, economic and environmental conditions to receive the same good-quality education.

In 2008, UNESCO held the $48^{\text {th }}$ International Conference on Education in Geneva. The theme of this conference is "inclusive education: the only way". The purpose of this conference is to promote the development of inclusive education in worldwide scope from the trans-regional perspective. State councilor Liu Yandong attended the conference and made an important speech. She pointed out, "Putting forward inclusive education reflects the respect to everybody and the protection to human rights. It conforms to the requirements of the times and the trend of future. It will have an important effect on establishing harmonious world." Liu Yandong expressed that inclusive education should be brought into China's medium-and-long-term educational planning to propel fair education which covers all the people, develop high-quality education which shares resources, and construct life-long education.

\section{The connotation of inclusive educational idea}

Salamanca Declaration, which was passed in the World Conference on Education for Special Needs in 1994, has specified five principles. The principles encompass the views of human rights, equality, democracy and values of inclusive education. These four kinds of views are discussed as follows.

\subsection{View of human rights}

Human rights are personal rights and democratic rights, which can be divided into three dimensions: survival rights, educational rights, and personal rights. The survival rights mean that every being has the basic substantial rights and should be respected, even for the students with special needs. The educational rights, which are basic human rights, advocate that everybody has the rights to be educated. The students with special needs also have the rights to acquire equal education to motivate the development of their mind and body and the exertion of potential. The personal rights emphasize that the students with special needs should not only be given the opportunities of receiving education, but also be respected in their human dignity and be given the chances to participate all kinds of activities. These three dimensions mainly emphasize the educational rights. The principal content of inclusive education is that all the schools should admit all the students, oppose discrimination and exclusion, attach importance to collective cooperation, meet different needs and realize inclusive education.

\subsection{View of equality}

Inclusive education advocates that everybody has the rights to receive education equally. The equality does not mean absolute equality. It attaches importance to the development of every student. Inclusive educational idea demonstrates that every student is unique and has his/her own characters, interests, abilities and learning needs. These differences should not be the reason of discrimination but the foundation to care for them and provide appropriate learning conditions. However, in current higher education, there still exists the phenomenon of judging success and failure according to marks. This is one of the problems to be solved.

\subsection{View of democracy}

Equal education involves the construction of democracy. Without fair education there is no democratic society. People's rights of educational equality can be secured forcefully in a society with strong democratic ideas. On the contrary, in a society which lacks democratic ideas, people lack the knowledge of democratic ideas and the pursuit of equal rights. This makes it difficult to ensure justice and equality in the field of education. This also makes the appearance of exclusion of the disadvantaged groups and abates their consciousness of active participation, which can reflect the democratic view of inclusive educational idea and requires every person who receives education to take part in the social decision-making in order to reconstruct the society.

\subsection{View of values}

Viewing from the value orientation of inclusive educational idea, the governing values are advocating teamwork. 
It is a general trend for the development of education to emphasize collective and cooperation. This is also an objective requirement for the development of international community. Inclusive educational idea, which is different from traditional educational idea, sets foot on collective to solve problem by cooperation. Its aim on cultivating people is collective and cooperation, for the jobs in the future society require people to be cooperative, especially for the people with different interests, abilities, personalities and cultural backgrounds. Inclusive educational idea advocates that common schools admit all the students. Because of the students' different needs, the role of teamwork becomes very important. A cooperative relation needs to be established between teachers, between teachers and students, between teachers and parents, and between parents. An inclusive atmosphere needs to be constructed together.

\section{The challenge from inclusive educational idea}

Inclusive educational idea advocates including all the students, opposing exclusion and discrimination, and meeting the different needs of different students. It emphasizes participation and teamwork, which is against the traditional educational idea. Consequently, the implementing of inclusive educational idea will bring about new challenge.

\subsection{Challenge to traditional educational idea}

Guided by traditional educational idea, higher education has entered the period of mass education in our country, but it still has not broken away from the shadow of superior education. Even though special education is introduced to some colleges and universities, it is still set in some separate departments and specialties, and does not break away from "dual-oriented education." Different degrees of explicit or implicit discrimination still exist in introduction to specialties, teaching activities or in the students' management. Such discrimination will make some students' mind warp, even serious psychological block. Education is the cornerstone of human civilization. Educational rights are basic human rights. Equal excess to education is the origin of social equality. Therefore, we should carry out inclusive educational idea, treat every student fairly, and avoid discrimination or exclusion.

\subsection{Challenge to educational system}

Compared with inclusive educational system, traditional educational system is a binary system which set colleges separately or set separate departments and specialties in a college. There will be great challenge to the construction of unified system, for constructing unified system is a systematic engineering, and it will cause the change of system. After that, specialty establishment, course structure, course option, practical process, etc. should be adjusted. The establishment of the differentiation examination system becomes particularly important. Constructing the unified system is the precondition of implementing inclusive educational idea, and the differentiation examination system is the necessary condition of the normal operation of unified educational system. Just like Aristotle said, "To different people with the same treatment is unfair as well as to the same people with different treatment".

\subsection{Challenge to the ranks of teachers}

Enforcing inclusive educational idea requires not only admitting all the students and opposing discrimination, but also meeting different needs of them and emphasizing participation and teamwork. This requirement is beyond expectation for most of the teachers. The traditional teaching methods, classroom management and examination system should be substituted by diverse teaching approaches, new classroom management varying from person to person and differentiation examination system. The students' study, life and development can never be affected by any divergence on their body, intelligence, emotion, language, culture and nationality.

\section{Countermeasure to the challenge of inclusive educational idea}

Today, implementing inclusive educational idea has become an upsurge of educational reformation in the developed countries and districts. However, it has a long way to go in China, for China is a multinational country and a populous nation with great number of disabled people. The problems of education for the children of the migrant workers and the hometown-remaining children in rural areas need to be put on the agenda. Here are some suggestions.

\subsection{Establishing inclusive educational system}

Establishing inclusive educational system is a systematic project. It is an efficient path for the security of human rights and for the realization of educational fairness. It is also an important measure to improve the quality of the people and to achieve a powerful nation of education. Establishing inclusive educational system needs great support and participation of the whole society, and the whole society's inclusive consciousness and regulation of conduct should be cultivated. Program of Action for Special Needs Education, published by UNESCO, points out that the decisive factor for implementing inclusive education is the support, participation and good wishes from the whole members of the society. The inclusive educational system includes the guidance from 
government, the support from finance, the action of schools and the admission of enterprises and community. Indeed, to common schools oriented by inclusive ideas, fighting against discrimination is the most effective path for the realization of education for all people, but we should realized that without the guidance of the government, the support from finance, and the participation of the whole society, we cannot carry out this great project. So, the whole society should realize clearly that after higher education enters the mass stage, the next aim is inclusive education. Enough preparation is required.

\subsection{Constructing inclusive educational atmosphere}

Among the three factors for talent cultivation, environment is one of them. To carry out inclusive education is to reconstruct the school's function and culture and reform the educational environment, which should be learner-centered in order to provide an educational environment that can embody fair participation, equal personality, mutual respect and understanding. Such educational atmosphere can help to insure the enforcement of inclusive education. Humanity environment is very important in the process of constructing inclusive educational environment. For one thing, students should be directed to care for and help each other, to recognize their identity of collaborators in the collective, to develop everyone's potential and to deal with everybody's problems with the power of the collective. For the other thing, the staff members should be equipped with inclusive educational idea, establishing the idea of respecting the students' principal status, caring about every student, and guiding the staff members to establish equal, democratic and comfortable relationship with the students.

\subsection{Enacting and improving relative rules, regulations and policies}

Enacting and improving relative rules, regulations and policies is the fundamental guarantee of carrying out inclusive educational idea. Inclusive education is a new project in the higher education of our nation, and there are no well-defined rules and regulations to insure it. The current rules, regulations and policies are inconsistent with inclusive educational idea in many aspects, resulting in the unfairness in education. Take higher education as an example. On the one hand, charges result in unequal chances of admission. The very high charges reduce the opportunities of admission for the students from low-income families, and make such students be in more disadvantageous position in the distribution of educational resources. On the other hand, there exists the problem of entrance marks. The entrance rate and entrance marks are completely different in different places in our country. Because of different birth places, there exist unfair phenomena of admitting opportunities. Such problems result in the discrimination and prejudice towards the students who are from low-income families and from the poverty-stricken areas, and need to be concentrated on.

\subsection{Cultivating proper ranks of teachers to adapt to inclusive education}

Cultivating proper ranks of teachers is the key-line to put inclusive education into practice. For quite a long time, the segregation between general education and special education makes teachers unaware of how to cope with the challenge of inclusive education. The only way is to strengthen in-service training, make them know the features of different kinds of students, respect the differences of each kind of students, concern about their needs, formulate personalized teaching plans and use diverse teaching methods to teach students in accordance with their aptitude, meet the special requirements of students with different learning backgrounds, experiences and abilities. Meanwhile, every student should be guided to set the aim of autonomous development reasonably and make it become the drive of autonomous learning and development according to social and economic development. In the long run, both normal education and qualified teacher training should increase the content of inclusive education so that teachers could master the corresponding knowledge and skills, and the problem of cultivating inclusive ranks of teachers can be solved from root causes.

\section{Conclusion}

All in all, our ideal is to make every child have fair rights and chances to get education, to make them better by using knowledge, to create beautiful life, and to make the human civilization light the future of all the people.

\section{References}

Liu Yanhui. (2009). Equal Access to Education in the View of Inclusive Education. Educational Review,2, 52-55.

Peng Xiaguang. (2008). Inclusive Education: A Path to the Future --- Reflection and Interpretation on Inclusive Educational Idea. Chinese Special Education, 12, 38-42.

Shi Meijun. (2008). Attempt and Exploration of Launching Inclusive Education for Colleges and Universities. Journal of Changchun University, 3, 86-92.

Wu Xiaoning and Yu Xiaoying. (2007). Reflection on Realizing China's Educational Fairness under Inclusive Educational Idea. Journal of Guizhou Normal university, 3, 72-76. 